\title{
The Biennial report: The collaboration between MAGI Research, Diagnosis and Treatment Center of Genetic and Rare Diseases and Near East University DESAM Institute
}

\author{
Mahmut Cerkez Ergoren ${ }^{1,2,}$, Elena Manara ${ }^{3}$, Stefano Paolacci ${ }^{3}$, Havva Cobanogullari ${ }^{1,2}$, Gulten Tuncel ${ }^{1,2}$, \\ Meryem Betmezoglu ${ }^{1,2}$, Matteo Bertelli ${ }^{4}$, Tamer Sanlidag ${ }^{1}$
}

\section{Background}

Scientific collaboration is more common now than it was before. In many areas of biomedical science, collaborations between researchers with different scientific backgrounds and perspectives have enabled researchers to address complicated questions and solve complex problems.

Particularly, international collaborations and improvements in science and technology have shed light on solving the mechanisms that are involved in the etiology of many rare diseases. Hence, the diagnosis and treatment options have been improved for a number of rare diseases. The collaboration between Near East University DESAM Institute and MAGI Research, Diagnosis and Treatment Center of Genetic and Rare Diseases brought out significant results. Importantly, this collaboration contributed to the rare disease research by the identification of novel rare genetic disease-causing variations commonly in pediatric cases. Consequently, many pediatric unsolved cases have been diagnosed.

The main scope of this article is to emphasize the outcomes of the collaboration between Near East University DESAM Institute and MAGI Research, Diagnosis and Treatment Center of Genetic and Rare Diseases which contributed greatly to the scientific literature by identifying novel rare genetic disease-causing variation.

Keywords: rare-disease, genomics, high-throughput DNA sequencing, variants, genetic disorders

${ }^{1}$ Near East University, DESAM Institute, Nicosia, Cyprus

${ }^{2}$ Near East University, Faculty of Medicine, Department of Medical Biology, Nicosia, Cyprus

${ }^{3}$ MAGI Euregio, Bolzano, Italy

${ }^{4}$ MAGI's LAB S.r.l., Rovereto, Italy

${ }^{*}$ Corresponding author: Assoc. Prof. Mahmut Cerkez Ergoren

e-mail: mahmutcerkez.ergoren@neu.edu.tr ORCID NO: 0000-0001-9593-9325

DOI: $10.2478 /$ ebtj-2020-0020

\section{Introduction}

Northern Cyprus is the third largest island in the Mediterranean Sea which has been at the crossroads of different civilizations throughout history The genetic characteristics of the Turkish-Cypriot population have been affected by different factors such as migrations, admixture and genetic drift (1). Despite of financial difficulties that appear especially in economy, research and development due to being not recognized all around the world, Near East University contributes the country's economy. It has been more than five years, since the university concentrated on research, diagnosis and development. In 2016, Research Center of Experimental Health Sciences (DESAM) were established to encourage scientific research and education in Cyprus. Today, DESAM has converted to research and education institute which involves different research groups including Rare Disease Research Group.

The first steps have been undertaken by European Biotechnology Thematic Network Association (EBTNA) to initiate the collaboration between Near East University DESAM Institute and Research, Diagnosis and Treatment Center of Genetic and Rare Diseases. MAGI is a pilot center for the diagnosis of rare genetic diseases and it is active in Italy, Europe and many developing countries. The center's main goal is to make clinical testing accessible to people who have rare genetic disease and their families. Furthermore, it has been implicated in numerous international collaborations to promote diagnosis and re- (c) 2020 Authors. This work was licensed under the Creative Commons AttributionNonCommercial-NoDerivs 4.0 License. 
search on genetic diseases.

"Rare disease" or "Orphan disease" terms are used to define circumstances that affect a small fraction of the population (2). In the USA, they are described as affecting less than 200.000 people Whereas, in Europe these diseases are explained as affecting less than one in 2000 people (3). However, rare diseases have a complicated nature therefore it is essential that each country or region has a unique definition of rare disease, by taking into consideration of their own population, culture, health care system and resources (4)

Importantly, the majority (50-75\%) of the rare diseases affect children and generally are severe multisystem disorders that composed of broad range of phenotypes. The estimated number of rare diseases is 7.000 and nearly $85 \%$ of them have an underlying genetic cause (5). Within this framework, rare diseases have an important effect on health, therefore, healthcare professionals should be more aware of the resources that exist to promote diagnosis, management and treatment of rare diseases (3).

In last years, advances in science and collaborations have en- lightened the way of rare diseases research and eventually the quality of life for patients living with rare diseases has been improved. Nevertheless, the etiology of many rare diseases has not been yet fully understood and there is no effective treatment available for most of the rare diseases (6). Additionally, many rare diseases account for tremendous healthcare costs globally due to the crisis of establishing a specific diagnosis (7). Thus, in order to find solutions for these problems, collaborators and most importantly patient groups should be actively involved in the research (6).

The outcomes of MAGI Research, Diagnosis and Treatment Center of Genetic and Rare Diseases. Near East University DESAM Institute Collaboration

International collaborations, sharing knowledge and experience, are essential steps to help patients with rare diseases. The collaboration between MAGI Group and Near East University DESAM Institute brought out important consequences in rare disease research. Since 2016, many novel rare genetic disease-causing mutations have been identified generally in pedi-

Table 1. Some studied diseases and their scientific/diagnostic significance to the literature

\begin{tabular}{|c|c|c|}
\hline Study type & Disease Phenotype & Scientific/ diagnostic significance \\
\hline Case 1 & Dyslexia & Disease associated SNP do not segregate within the family \\
\hline Case 2 & Undefined Skeletal Syndrome & $\begin{array}{l}\text { Detected variant do not match with clinical phenotype- whole } \\
\text { genome sequencing required }\end{array}$ \\
\hline Case 3 & Wiedemann-Rautenstrauch syndrome & $\begin{array}{l}\text { Combined heterozygosity including novel variant within the } \\
\text { POLR3A gene (detected variant: POLR3A c.3568C }>\text { T; p.Gln- } \\
\text { 1190Ter (9) }\end{array}$ \\
\hline Case 4 & Joubert Syndrome & $\begin{array}{l}\text { Pathogenic variant could not be detected- whole genome sequen- } \\
\text { cing suggested }\end{array}$ \\
\hline Case 5 & Dilated Cardiomyopathy & $\begin{array}{l}\text { Pathogenic variant could not be detected- whole genome sequen- } \\
\text { cing suggested }\end{array}$ \\
\hline Case 6 & Glutaric Aciduria Type 1 & $\begin{array}{l}\text { Rare late-on-set case, homozygous variant was detected within } \\
\text { the GCDH gene (detected variant: GCDH .1204C > T; p.R402W) } \\
\text { (10). }\end{array}$ \\
\hline Case 7 & Immundeficiency & $\begin{array}{l}\text { Detected variant's pathogenicity need to be confirmed by methy- } \\
\text { lation study. }\end{array}$ \\
\hline Case 8 & Treacher-Collins Syndrome & $\begin{array}{l}\text { Incompletely penetrant novel variant found within the POLR1D } \\
\text { gene (detected variant: POLR1D c.299T<C; p.Leu100Pro (11). }\end{array}$ \\
\hline Case 9 & Congenital heart disorder & No pathogenic variant detected. \\
\hline Family 1 & Myotonia Congenita & $\begin{array}{l}\text { Most frequent known pathogenic variant was detected within the } \\
\text { CLCN1 gene (detected variant: CLCN1 c. } 803 \mathrm{C}>\mathrm{T} \text {; p. Thr } 268 \mathrm{Met} \text { ) }\end{array}$ \\
\hline Family 2 & Achondroplasia & $\begin{array}{l}\text { Very well-known variant was detected within the FGFR3 gene } \\
\text { (detected variant: FGFR3 c.1138G>A p.G380R) (12) }\end{array}$ \\
\hline Family 3 & Charcot-Marie-Tooth & Variant found in the healthy brother \\
\hline Family 4 & $\begin{array}{c}\text { Tricho-Rhino-Phalangeal Syndrome } \\
\text { Type } 1\end{array}$ & $\begin{array}{l}\text { Novel deletion variant were detected within the TRPS1 gene (dete- } \\
\text { cted variant: TRPS1 c.2854_2858del; p.Asn952ArgfsTer2) (13). }\end{array}$ \\
\hline Family 5 & CACP syndrome & $\begin{array}{l}\text { Pathogenic variant could not be detected- whole genome sequen- } \\
\text { cing suggested }\end{array}$ \\
\hline
\end{tabular}


atric cases. As it is discussed above, majority of the rare diseases have an underlying genetic cause. Importantly, improvements in science and technology have enabled scientists to learn more about the etiology of rare diseases. Especially, Next-generation sequencing (NGS) technology has been widely used to find genes that cause rare genetic diseases (8). With this in mind, due to the lack of NGS technology in Northern Cyprus, MAGI group provided a wide range of support such as finding funding for disease research. Additionally, high throughput technology such as NGS was performed to identify novel rare genetic disease-causing mutations for many pediatric unsolved cases.

Furthermore, 18 patients and their families were included in the first study in November 2017. Study groups were divided into two subgroups: research and diagnostic groups according to their possible novel contribution to the literature. For example, a patient with Wiedemann-Rautenstrauch syndrome (Case 3) (WRS; MIM 264090) were examined within research group as a disease is extremely rare (9). Additionally, a newborn boy with Treacher-Collins Syndrome (Case 8) were placed in the research part as a novel variant withing the RNA polymerase I subunit D (POLR1D, MIM 613717) gene was identified. On the other hand, a family with myotonoia congenita (Family 1) was included in the diagnosis group as the disease-causing variant CLCN1 c.803C>T; p.Thr268Met (rs80356687) were most frequent known variant. Patient and their clinical statues have been explained on table 1. A wide range of disease groups were examined for the first part of this collaboration including skeletal abnormalities, neurodegenerative disorders, cardiac problems, congenital dysmorphologies. more patients with families were included in June 2018 as a second part of the project including different diseases groups such as congenital dysmorphologies, growth development retardation and childhood obesity. Moreover, 12 out of 18 (nearly 66.7\%) of cases from diagnosis group have been reported up-to-date.

In 2018, first outcomes of this collaboration were presented at the European Biotechnology Congress 2018 in Athens, Greece between 26th-28th April 2018 and published at journal of biotechnology (14). This collaboration and its contribution to Cypriot community was presented at the Second International Biomedical Engineering Congress (IBMEC 2018) between 24th-27th May 2018 in Nicosia, Cyprus. Furthermore, two accomplished rare studies were presented at the 43rd FEBS Congress between 4-9 July 2018 in Prague, Czech Republic (11, 15) organized by Federation of European Biochemical Societies (FEBS) and published at FEBS Open Bio. Furthermore, a poster was presented at American Society of Human Genetics 2018 (ASHG) meeting and a patient with WRS was presented at Erciyes Medicine Day 2018 in Kayseri, Turkey and published in Erciyes Medical Journal (9). The results from families were presented at international scientific meetings such as European Society of Human Genetics (ESHG) Meeting 2020, Recent Advances in Rare Diseases (RARD) 2019 Conference and European Biotechnology Congress $2019(14,16)$. Additionally, two significant studies were presented at Erciyes Medical Genetic Days congress 2019 in Kayseri (10,13). To sum up, in last two years seven international and three national oral presentation were present conferences and meetings as well as ten conference papers were published in journals. Lastly, five publishable data obtained from cases with unique examples that include families with Turkish and Cypriot heritages. Recently, one of these five cases were published on European Journal of Human Genetics in June 2020 (9).

\section{Discussion}

Undoubtedly, collaborations between researchers and teamwork lead to improvements in rare diseases diagnosis and treatment. The collaboration between Near East University DESAM Institute and MAGI Research, Diagnosis and Treatment Center of Genetic and Rare Diseases has had a significant contribution to the rare disease research. By this collaboration, novel rare genetic disease-causing variations have been discovered and many pediatric unsolved cases have been diagnosed. Besides these consequences, since genetic databases are absent in the region of Middle Eastern, Near East University DESAM Institute Molecular Medicine Laboratory increases the capacity to produce DNA sequence data which may lead to expansion of the number of contributors to DNA sequence databases. By this way, further bioinformatics analysis can be performed and more information can be learned about the mechanisms that are involved in the etiology of genetic diseases so diagnosis and treatment options can also be improved. Additionally, the accumulated variation data will help us to determine population-specific allele frequencies as well as strengthens scientific institution in the country. Moreover, our foundation and success also create a more equitable global scientific establishment. Currently, the collaborators have joint two important international projects including Sars-CoV-2 treatment approaches. Lastly, these studies might be helpful to raise awareness of the government of Northern Cyprus and to point out the importance of research and early diagnosis.

\section{Conclusion}

To conclude, improvements in science and technology have been resulted in better diagnosis and treatment options for rare diseases. Especially, this example collaboration makes possible to progress in rare disease research and improve the quality of life for patients with rare diseases.

Since 2017, Near East University DESAM Institute and MAGI Research, Diagnosis and Treatment Center of Genetic and Rare Diseases collaboration has shed light on numerous unsolved pediatric cases by the identification of disease-causing variants. Since it is accepted and publicly recognized that rare diseases are a worldwide public health problem, there will be a growing interest in rare disease research in the future.

\section{References}

1. Georgiou A, Demetriou CA, Christou YP, et al. Genetic and Environmental Factors Contributing to Parkinson's Disease: A Case-Control Study in the Cypriot Population. Front Neurol. 2019;10:1047. Published 2019 Oct 17. 
doi:10.3389/fneur.2019.01047

2. Zhao M, Wei DQ. Rare Diseases: Drug Discovery and Informatics Resource. Interdiscip Sci. 2018;10(1):195-204. doi:10.1007/s12539-017-0270-3

3. Pogue RE, Cavalcanti DP, Shanker S, et al. Rare genetic diseases: update on diagnosis, treatment and online resources. Drug Discov Today. 2018;23(1):187-195. doi:10.1016/j. drudis.2017.11.002

4. Weber S, Grüters-Kieslich A. Seltene Erkrankungen. Bundesgesundheitsbl 2017; 60, 477-478. https://doi. org/10.1007/s00103-017-2542-9

5. Wright CF, FitzPatrick DR, Firth HV. Paediatric genomics: diagnosing rare disease in children (published correction appears in Nat Rev Genet. 2018 Feb 19;:). Nat Rev Genet. 2018;19(5):253-268. doi:10.1038/nrg.2017.116

6. Gopal-Srivastava R, Kaufmann P. Facilitating Clinical Studies in Rare Diseases. Adv Exp Med Biol. 2017;1031:125140. doi:10.1007/978-3-319-67144-4_6

7. Groft SC. Rare diseases research: expanding collaborative translational research opportunities. Chest. 2013;144(1):16-23. doi:10.1378/chest.13-0606

8. Posey, J. E. (2019). Genome sequencing and implications for rare disorders. Orphanet Journal of Rare Diseases, 14(1), 1-10. https://doi.org/10.1186/s13023-019-1127-0

9. Temel SG, Ergoren MC, Manara E, et al. Unique combination and in silico modeling of biallelic POLR3A variants as a cause of Wiedemann-Rautenstrauch syndrome (published online ahead of print, 2020 Jun 18). Eur J Hum Genet. 2020; 10.1038/s41431-020-0673-1. doi:10.1038/ s41431-020-0673-1

10. Gelener P, Severino M, Diker S, et al. Adult-onset glutaric aciduria type I: rare presentation of a treatable disorder. Neurogenetics. 2020; 21(3):179-186. doi:10.1007/s10048020-00610-9

11. Sah H, Sanlidag B, Manara E, Mocan G, Temel SG, Bertelli M, Ergoren MC. Phenotype does not necessarily follow genotype: Identification of an incompletely penetrant novel POLR1D variant as a likely cause of Treacher Collins syndrome. FEBS Open Bio 2018; 8(S1): 107-510. https:// doi.org/10.1002/2211-5463.12453

12. Ergoren MC, Aliyeva L, Eren E, Manara E, Paolacci S, Mocan M, Temel SG, Bertelli M. Psychomotor delay in a child with Achondroplasia . Abstracts from the 51st European Society of Human Genetics coNFERENCE: posters. Eur J Hum Gene 2018; 27: 1-688

13. Akcan N, Betmezoglu M, Manara E, Paolacci S, Temel SG, Mocan G, Bundak R, Ergoren MC. Characterization of a novel frameshift mutation in the TRPS1 gene as a cause of Trichorhinophalengeal syndrome type 1 in a Cypriot Heritage Family. Erciyes Medical Journal, 2019; 41(S1): 28. https://doi.org/10.14744/etd.2019.55631

14. Maltese PE, Paolacci S, Manara E, Marceddu G, Beccari T, Ergoren MC, Bertelli M. Use of exome sequencing in identifying genes responsible for rare genetic diseases. Journal of Biotechnology. 2018; 280: S7. https://doi.org/10.1016/j. jbiotec.2018.06.325

15. Betmezoglu M, Terali K, Manara E, Paolacci S, Mocan G, Temel SG, Dirik E, Bertelli M, Ergoren MC. Characterization and in silico modelling of bi-allelic POLR3A mutations as a cause of Wiedemann-Rautenstrauch syndrome. FEBS Open Bio 2018; 8(S1): 107-496. https://doi. org/10.1002/2211-5463.12453

16. Ergoren MC, Manara E, Paolacci S, Temel SG, Mocan G, Dundar M, Bertelli M. Application of high-throughput DNA sequencing to score population-specific variants for rare disorders. Journal of Biotechnology. 2019; 305 (15): S25 